
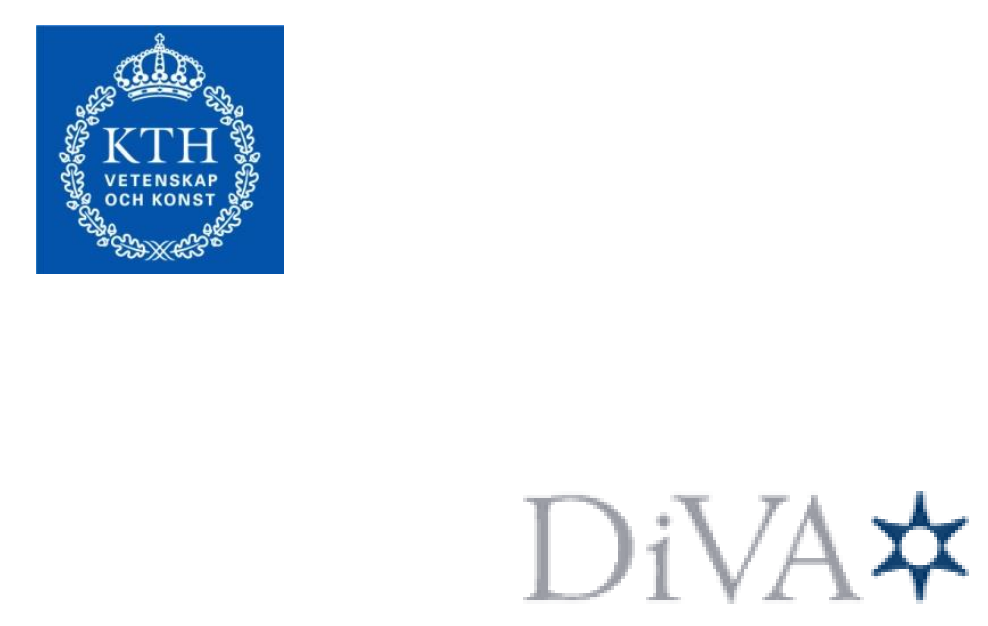

http://kth.diva-portal.org

This is an author produced version of a paper published in IEEE 26th International Conference on Micro Electro Mechanical Systems (MEMS), 2013.

This paper has been peer-reviewed but does not include the final publisher proofcorrections or proceedings pagination.

(C) 2013 IEEE. Personal use of this material is permitted. Permission from IEEE must be obtained for all other uses, in any current or future media, including reprinting/republishing this material for advertising or promotional purposes, creating new collective works, for resale or redistribution to servers or lists, or reuse of any copyrighted component of this work in other works.

Citation for the published paper:

Fredrik Forsberg, Farizah Saharil, Göran Stemme, Niclas Roxhed, Wouter van der Wijngaart, Tommy Haraldsson and Frank Niklaus. Low temperature adhesive wafer bonding using $\operatorname{OSTE}(+)$ for heterogeneous $3 \mathrm{D}$ MEMS integration.

IEEE 26th International Conference on Micro Electro Mechanical Systems (MEMS), 2013.

Access to the published version may require subscription.

Published with permission from: IEEE 


\title{
LOW TEMPERATURE ADHESIVE WAFER BONDING USING OSTE(+) FOR HETEROGENEOUS 3D MEMS INTEGRATION
}

\author{
Fredrik Forsberg, Farizah Saharil, Göran Stemme, Niclas Roxhed, \\ Wouter van der Wijngaart, Tommy Haraldsson and Frank Niklaus \\ KTH Royal Institute of Technology, Microsystem Technology Lab, Stockholm, Sweden
}

\begin{abstract}
We demonstrate, for the first time, the use of off stoichiometry thiolene-epoxy, OSTE $(+)$ for adhesive wafer bonding. The dual cure system, with an initial UV-curing step followed by a second thermal cure, allows for high bond strength and potentially high quality material interfaces. We show that cured $\operatorname{OSTE}(+)$ is easily removed in oxygen plasma and that the characteristics of OSTE $(+)$ make it a potential candidate for use in heterogeneous $3 \mathrm{D}$ MEMS integration. Furthermore, we show how the bond energies of wafers bonded with $\operatorname{OSTE}(+)$ adhesive compares with the bond energies of wafers bonded with Cyclotene 3022-46 (BCB) and mr-I 9150XP nanoimprint resist.
\end{abstract}

\section{INTRODUCTION}

Wafer-level heterogeneous integration of different materials is an emerging fabrication method for the realization of complex microelectromechanical systems (MEMS) [1]. A typical integration process consists of using wafer bonding techniques such as anodic, adhesive, eutectic and fusion wafer bonding to attach wafers to each other [2-4]. Adhesive wafer bonding has advantages such as the capability of attaching wafers with a high surface topography (due to the capability of the polymer to deform and adapt to the wafer surfaces) and wafers consisting of materials with different temperature coefficient of expansion can be bonded [4]. Furthermore, the use of spin-coating procedures allows for a high level of freedom in achieving different thicknesses of the intermediate adhesive layer. Depending on the polymer used in the bond, different properties such as low temperature bonding processes, selective removal of the cured polymer adhesive, high bond strength, thermal stability and high quality bond interfaces can be achieved to suit the application of interest. Polymers used for adhesive wafer bonding include benzocyclobutene (BCB) and nano-imprint resists [5]. However, $\mathrm{BCB}$ requires curing temperatures of above $200^{\circ} \mathrm{C}$ and it is difficult to remove $\mathrm{BCB}$ after curing, while nano-imprint resists suffers from limited bond strength compared to BCB [5].

New polymers that combine the different strengths of established polymer systems are of interest to increase the applicability of adhesive wafer bonding. Recently, Saharil et. al have introduced the off-stoichiometry thiol-ene epoxy, $\operatorname{OSTE}(+)$ as a dry adhesive for bonding nanoporous silicon (Si) membranes to microfluidic devices [6]. $\operatorname{OSTE}(+)$ has a dual cure mechanism where the first curing step is driven by UV-exposure and the second curing step is accelerated by the use of elevated bonding temperatures. In this paper, the use of $\operatorname{OSTE}(+)$ for adhesive wafer bonding is evaluated by determining the adhesive bond energies of $\mathrm{OSTE}(+)$ to Si interfaces in burst pressure tests and comparing it to the bond energies of reference samples bonded with Cyclotene 3022-46 (BCB) and mr-I 9150XP nanoimprint resist. Furthermore, bond interfaces between $\mathrm{Si}$ and glass wafers are demonstrated to determine the bond interface quality. Finally, to demonstrate membrane transfer and easy removal of the cured $\operatorname{OSTE}(+)$ polymer, OSTE(+)-bonded Si wafers are used in low temperature $\left(90^{\circ} \mathrm{C}\right)$ transfer of a thin mono-crystalline Si film to a target $\mathrm{Si}$ wafer that is subsequently micromachined into free-hanging cantilevers.

\section{FABRICATION}

An OSTE(+) formulation consisting of $80 \%$ thiol excess (tetrathiol:triallyl:epoxy 1.8:1:0.8) and $0.5 \%$ TPO-L photo-initiator was prepared. The polymer formulation was diluted $1: 1$ by weight with toluene. The diluted OSTE(+) was used to spin-coat $100 \mathrm{~mm}$ diameter Si wafers at $6000 \mathrm{rpm}$ (Fig. A1). No increased temperature was used in this step to avoid unwanted curing of the polymer. Instead, the toluene solvent was removed by exposing the coated wafers to vacuum at room temperature for 10 minutes. The first cure of the $\operatorname{OSTE}(+)$ dual cure system was initiated by UV exposure in a mask aligner using between $120 \mathrm{~mJ} / \mathrm{cm}^{2}$ and $400 \mathrm{~mJ} / \mathrm{cm}^{2}$ in a broadband exposure with a $\mathrm{Hg}$ light source (Fig. A2). This curing step drives a reaction between the tetrathiol and the triallyl molecules to create a loosely cross-linked polymer network. After this step the polymer coating is a solid with a slightly sticky surface. Subsequently, the coated wafers were bonded in a wafer bonder with a $5000 \mathrm{~N}$ bond force (Fig. A3) at a low bonding temperature (between $25^{\circ} \mathrm{C}$ $120^{\circ} \mathrm{C}$ ) to different substrates as described below. The thermal bond step drives the second curing mechanism in $\operatorname{OSTE}(+)$ where epoxy and remaining thiol groups in the polymer-blend polymerize via an anionic mechanism. At the end of the thermal cure, all thiol and epoxy groups have reacted to form a highly cross-linked polymer network with a high glass transition temperature $\left(\mathrm{T}_{\mathrm{g}}\right)$ and a high Young's modulus.

Three different bonding experiments were performed. Firstly, $500 \mu \mathrm{m}$ thick glass wafers were bonded to $\operatorname{OSTE}(+)$ coated $\mathrm{Si}$ wafers at two different temperatures $\left(25^{\circ} \mathrm{C}\right.$ and $\left.120^{\circ} \mathrm{C}\right)$ to enable visual inspection of the bond interfaces through the glass wafer. Secondly, to investigate the potential for use of the method in micromachining (Fig. $1 \mathrm{~B}$ and $1 \mathrm{C}$ ), a $125 \mu \mathrm{m}$ thick $100 \mathrm{~mm} \mathrm{Si}$ wafers was spin coated with $\operatorname{OSTE}(+)$ and then bonded to a $525 \mu \mathrm{m}$ thick $100 \mathrm{~mm} \mathrm{Si}$ wafer at a bonding temperature of $90^{\circ} \mathrm{C}$. The $125 \mu \mathrm{m}$ thick $\mathrm{Si}$ wafer was then thinned down to a thickness of less than $10 \mu \mathrm{m}$ in an ICP dry etcher. The thin Si film was subsequently micromachined into cantilever structures. This was followed by removing the OSTE $(+)$ bonding polymer in an oxygen plasma process 
A Wafer bonding
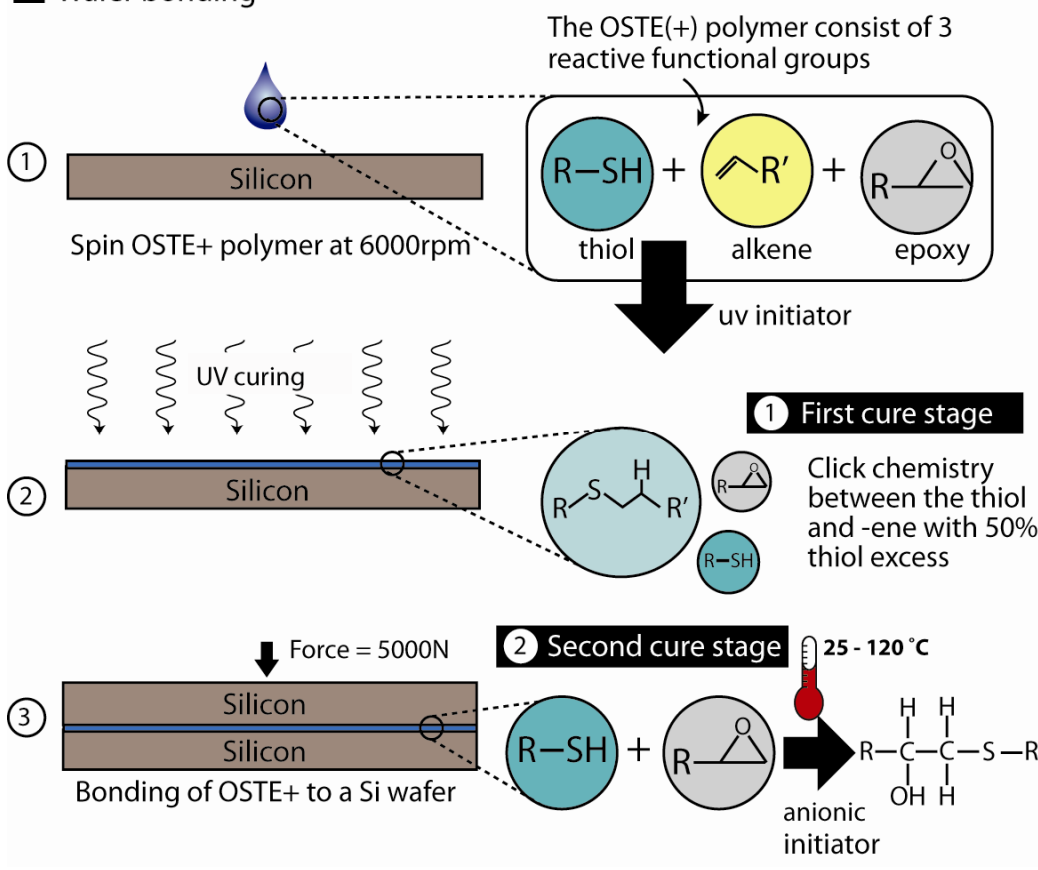

B Thinning down bulk silicon

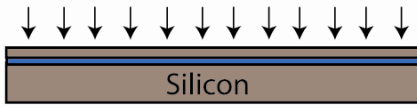

Thinning down the bulk Si in the ICP

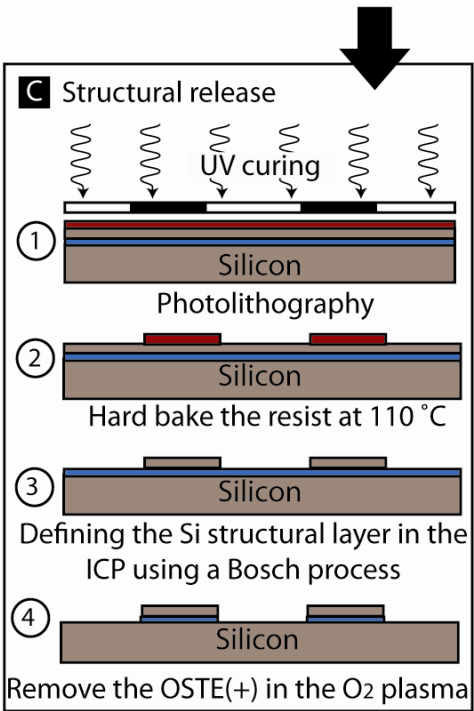

Figure 1: (A1) OSTE(+) is spin coated at $6000 \mathrm{rpm}$ and the solvent is removed by placing wafers in vacuum. (A2) First curing step by exposing wafers in UV-light. (A3) The wafers are bonded. (B) Thinning of bonded bulk Si. (C1-3)

Lithography and etching of the transferred Si film. (C4) The OSTE(+)-polymer is removed in O2-plasma.
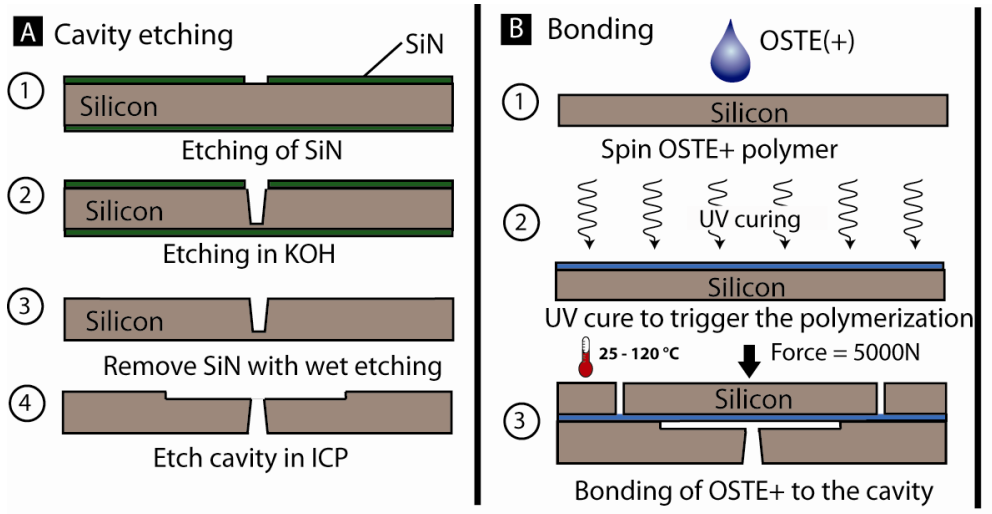

C Burst pressure evaluation

(1)

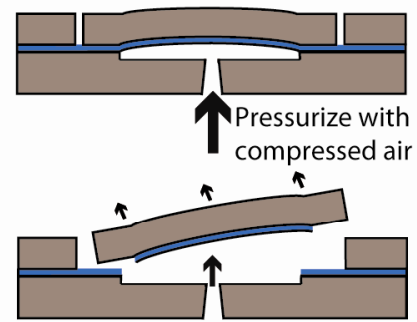

Record the burst pressure with Labview and transform the pressure into equivalent bonding energy

Figure 2: Fabrication of chips with bonded lids for burst pressure experiments.

that under-etched the fabricated structures into free-hanging cantilever beams. This was done in a standard TePla barrel etcher using an etch process with a power of $1000 \mathrm{~W}$ and an oxygen gas flow rate of $500 \mathrm{ml} / \mathrm{min}$ for approximately $30 \mathrm{~min}$. Thirdly, for bond strength evaluation through burst pressure testing, $525 \mu \mathrm{m}$ thick Si wafers with etched round orifices were prepared. The fabrication sequence of these are described in Fig. 2A and consist of $\mathrm{KOH}$ etching small through holes in a $525 \mu \mathrm{m}$ thick silicon nitride ( $\mathrm{SiN}$ ) coated $\mathrm{Si}$ wafer. The $\mathrm{SiN}$ was removed from the wafers. Large and precise circular holes were masked and etched into the Si wafer with an ICP dry etching tool. The wafers with etched cavities were then wafer bonded to plain $125 \mu \mathrm{m}$ thick Si wafers, spin coated with $\operatorname{OSTE}(+)$, according to the procedure described in Fig. 2B. Both diluted and undiluted OSTE $(+)$ were used in the experiments. As a last step, the plain wafer on top of the wafer with the cavities was diced with a dice saw to create individual lids on top of the etched orifices (Fig 2B3). The wafer stack was then etched through with a line pitch of 22 $\mathrm{mm}$, resulting in square sample dies with bonded lids on top as show in Fig. $2 \mathrm{C} 1$.

\section{EXPERIMENTAL}

The bond energies of wafer bonds using formulations of $\mathrm{OSTE}(+)$ polymer, BCB and mr-I 9150XP were evaluated. The OSTE $(+)$-formulations consisted of undiluted $\mathrm{OSTE}(+)$ that used DMP-30 as an anionic thiol-epoxy initiator and $\operatorname{OSTE}(+)$ diluted $1: 1$ by weight with toluene that used an anionic photolatent curing agent (provided by BASF). The BCB reference samples used the adhesion promoter AP-3000 to increase the bond strength. Dies with etched circular through holes and adhesively bonded Si lids on top were put in a holder and pressurized 
from the backside with nitrogen gas (Fig. 2C). The pressure was increased until the lids delaminated from the prepared dies. The pressure at the start of delamination (burst pressure) was converted into bond energies according to equation 1 [7].

$$
p_{c r}=\left(\frac{32}{3\left(1-v^{2}\right)}\left(\frac{h}{a}\right)^{3}\right)^{\frac{1}{2}}\left(\frac{E \gamma_{a}}{a}\right)^{\frac{1}{2}}
$$

Where $h$ is the wafer thickness, $a$ is the diameter of the circular orifice, $v$ is the Poisson ratio, $E$ is the Young's modulus for $\mathrm{Si}[8]$ and $\gamma_{\mathrm{a}}$ is the adhesive fracture energy per square meter. All experiments used Si lid wafers with a thickness of between $125 \mu \mathrm{m}$ and $132 \mu \mathrm{m}$, except for the samples bonded with undiluted OSTE $(+)$ and mr-I 9150 XP that instead used $300 \mu \mathrm{m}$ thick lids.

\section{RESULTS AND DISCUSSION}

\section{Bond energy:}

The measured bond energies are presented in Figure 3. BCB-bonded samples showed by far the highest bond energy in with a measured average energy in excess of 35 $\mathrm{J} / \mathrm{m}^{2}$, compared to bond energies of around $30 \mathrm{~J} / \mathrm{m}^{2}$ reported in literature [9]. Samples bonded with undiluted OSTE $(+)$ using DMP-30 as an initiator on the other hand had an average bond energy of above $20 \mathrm{~J} / \mathrm{m}^{2}$. This can be compared with the measured bond energy for the nano-imprint resist reference, mr-I 9150XP, that had measured bond energies of around $5 \mathrm{~J} / \mathrm{m}^{2}$. OSTE $(+)$ diluted $1: 1$ by weight with toluene on the other hand had a very weak wafer bond.

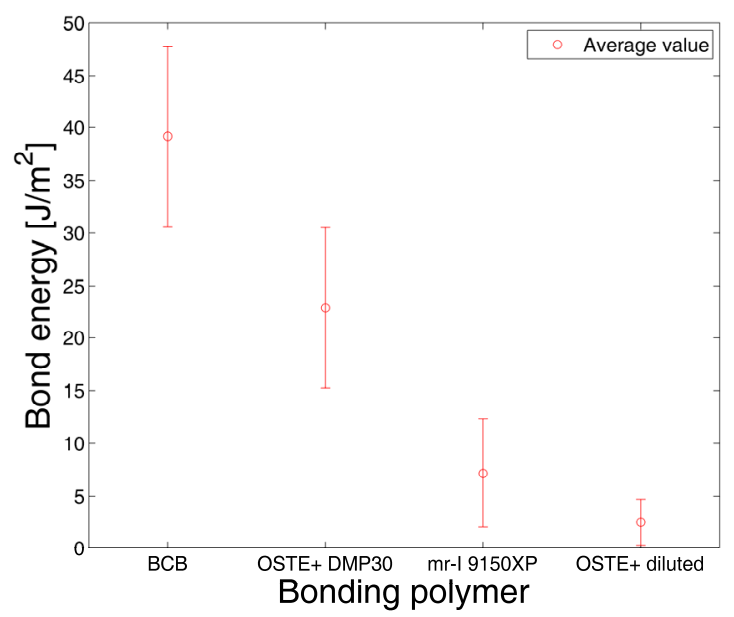

Figure 3: Evaluated bond energies measured by burst pressure experiments. The bars represent one standard deviation of measurement data. Each data point is based on between 10 and 14 individual samples from experiments.

\section{Bond interfaces:}

Figure $4 \mathrm{a}$ and $4 \mathrm{~b}$ show the bonding interfaces between $\mathrm{Si}$ and glass wafers. The wafer in Figure $4 \mathrm{a}$ is bonded at $120^{\circ} \mathrm{C}$ while the wafer in $4 \mathrm{~b}$ is bonded at $25^{\circ} \mathrm{C}$. In both cases, the vast majority of the bonded areas are void-free under optical microscopy inspections, although distributed imperfections exist. Generally, better bond interfaces occurred when a lower dose of UV-light (i.e. $120 \mathrm{~mJ} / \mathrm{cm}^{2}$ ) was applied in the first curing step.

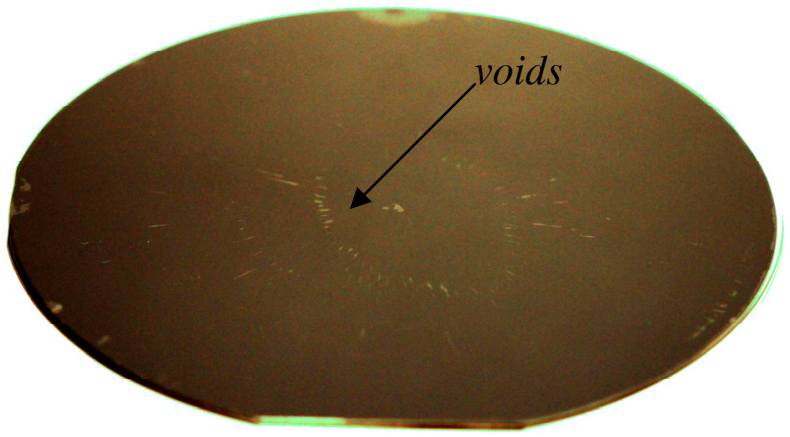

a)

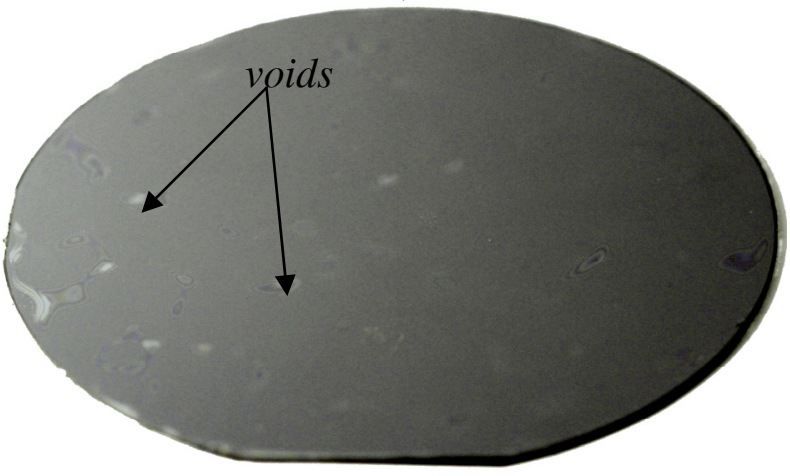

b)

Figure 4: a) Glass wafer bonded at $120^{\circ} \mathrm{C}$ to $\mathrm{Si}$ wafer using OSTE(+) DMP-30 diluted with 1:1 toulene. b) Glass wafer bonded at $25^{\circ} \mathrm{C}$ to Si wafer using OSTE(+) DMP-30 diluted with 1:1 toulene. The color map of the images has been adjusted to enhance the visibility of imperfections.

\section{Micromachining:}

Figure 5 shows a bonded $\mathrm{Si}$ wafer where the transferred $\mathrm{Si}$ wafer has been thinned down to less than 10 $\mu \mathrm{m}$ thickness with no visible delamination. No voids or irregularities were observed on the thin membrane surface, indicating that the bond polymer withstands plasma processing procedures. The thin $\mathrm{Si}$ layer was micromachined into cantilevers as described in the fabrication section. A SEM image of a fabricated cantilever is shown in Fig. 6.

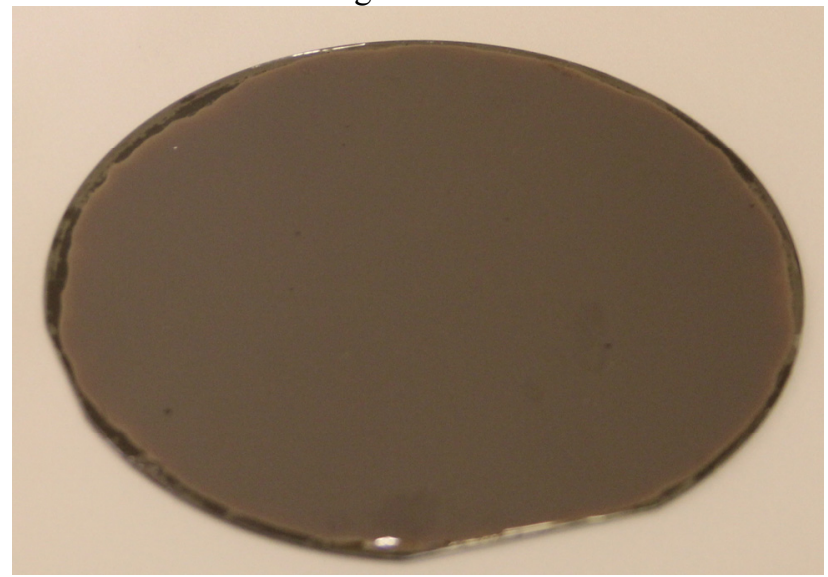

Figure 5: Si wafer stack bonded using OSTE(+). The top Si wafer is thinned down to a thickness of less than $10 \mu \mathrm{m}$. 


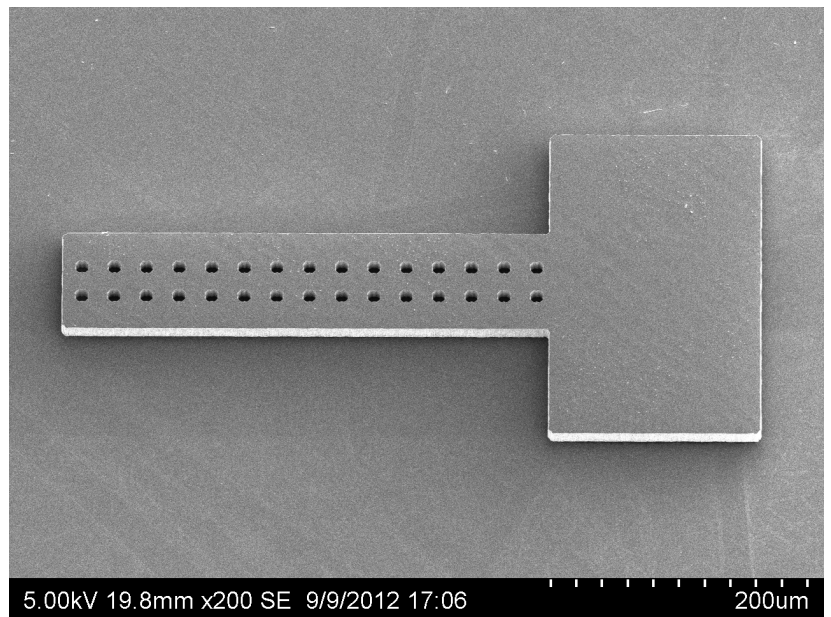

Figure 6: SEM of micromachined cantilever structure that has been free-etched in an oxygen-plasma.

Table 1: Comparison of results from the adhesive wafer bonding experiments with the different polymers.

\begin{tabular}{|c|c|c|c|c|c|}
\hline Polymer & $\begin{array}{c}\text { Bond } \\
\text { strength }\end{array}$ & $\begin{array}{c}\mathbf{O}_{2} \text {-plasma } \\
\text { removable }\end{array}$ & $\begin{array}{c}\text { Low temp } \\
\text { bonding }\end{array}$ & $\begin{array}{c}\text { Void free } \\
\text { interfaces }\end{array}$ & $\begin{array}{c}\text { Photo } \\
\text { lithography }\end{array}$ \\
\hline $\begin{array}{c}\text { OSTE(+) DMP 30 } \\
\text { undiluted }\end{array}$ & + & + & ++ & + & + \\
\hline $\begin{array}{c}\text { OSTE(+) diluted } \\
\text { 1:1 toulene }\end{array}$ & -- & + & ++ & + & + \\
\hline BCB & ++ & - & - & ++ & + \\
\hline mr-1 9150XP & - & + & - & ++ & - \\
\hline
\end{tabular}

The main adhesive bonding characteristics have been summarized in table 1 for the evaluated polymers. Undiluted $\operatorname{OSTE}(+)$ combines a high bond strength, low temperature bonding and is removable in oxygen plasma. Diluted OSTE $(+)$ has the same characteristics, except that it lacks in bond strength compared with both the reference nano-imprint resist and $\mathrm{BCB}$.

\section{CONCLUSIONS}

Undiluted $\operatorname{OSTE}(+)$ combines a high bond energy, while still being easily removable in oxygen plasma. Furthermore, heterogeneous transfer processes have been demonstrated by the fabrication of Si cantilevers. The bond energy is reduced for samples based on diluted OSTE(+). Void-free interfaces between glass wafers are potentially achievable with optimized adhesive bonding parameters, although the wafer bonds in this work showed a few bond defects over the wafer area. Formulations of OSTE $(+)$ show promise as a low temperature adhesive bonding polymer that combines many useful characteristics such as a high bond energy (for undiluted $\operatorname{OSTE}(+)$ and the ability to remove $\operatorname{OSTE}(+)$ polymer in oxygen plasma. This makes $\operatorname{OSTE}(+)$ a promising candidate for heterogeneous integration technologies.

\section{ACKNOWLEDGEMENT}

This work has been funded by the European Research Council (ERC) under grant agreements 267528 xMEMs and 277879 M\&M's.

\section{REFERENCES}

[1] M. Lapisa, G. Stemme and F. Niklaus, "Wafer-Level
Heterogeneous Integration for MOEMS, MEMS, and NEMS", IEEE Journal of Selected Topics in Quantum Electronics, No.99, pp.1-16, 2011.

[2] M. Alexe and U. Gösele, Wafer bonding: Applications and Technology, Springer-Verlag, 2004.

[3] M. Abouie, Q. Liu and G. Iveym, "Eutectic and solid-state wafer bonding of silicon with gold", Materials Science and Engineering B, vol. 177, pp. 1748-1758, 2012.

[4] F. Niklaus, G. Stemme, J.-Q. Lu, R.J. Gutmann, "Adhesive wafer bonding", Journal of Applied Physics, Vol.99, No.3, pp.031101/1-031101/28, 2006.

[5] F. Niklaus, A. Decharat, F. Forsberg, N. Roxhed, M. Lapisa, M. Populin, F. Zimmer, J. Lemm and G. Stemme, "Wafer Bonding with Nano-Imprint Resists as Sacrificial Adhesive for Fabrication of Silicon-On-Integrated-Circuit (SOIC) Wafers in 3D Integration of MEMS and ICs", Sensors and Actuators A: Physical, Vol.154, pp.180-186, 2009.

[6] F.Saharil, K.B. Gylfason, Y. Liu, T. Haraldsson, P. Bettotti, N. Kumar and W. van der Wijngaart, "Dry transfer bonding of porous silicon membranes to $\operatorname{OSTE}(+)$ polymer microfluidic devices", Proc. IEEE MEMS conf., Jan 2012, pp. 232-234.

[7] S.J. Bennett, K.L. Devries and M.L Williams, "Adhesive fracture mechanics," Int. Journal of Fracture, vol. 10, No. 1, pp. 33-43, 1974.

[8] M.A. Hopcroft, W.D. Nix, and T.W. Kenny, "What is the Young's Modulus of Silicon?", J. Microelectromechanical Systems, vol. 19, no. 2, April, 2010.

[9] Y. Kwon, J. Seok, J.Q Lu, T.S. Cale and R.J Gutmann, "Critical Adhesion Energy of BenzocyclobuteneBonded Wafers", J. Electrochem. Soc., vol. 153, no.4, pp. G347-G352, 2006.

\section{CONTACT}

Fredrik Forsberg, Microsystem Technology Lab, School of Electrical Engineering, KTH Royal Institute of Technology. Email: fredrik.forsberg@ee.kth.se 